\title{
A Conceptual Approach of Building Web Based Learning Tool
}

\section{Krasimir Kalev ${ }^{a}$}

a NVU Vasil Levski, faculty Artillery, AD and CIS, 1 Karel Shkorpil str., Shumen 9700, Bulgaria http://aadcf.nvu.bg

\section{A BSTRACT}

This work introduces a conceptualized approach of building web based learning tool for providing knowledge for specific topic and student model for student educational interactivity evaluation. The main characteristic of the presented approach for development learning application that is intended for web access is the consistency of the three key aspects of the digital form of a learning process learning objectives, information flow organization and software instruments.

ARTICLE INFO

RECEIVED: 09 Oct 20xx

REVISED: 10 Nov 20xx

ACCEPTED: 30 Nov 20xx

ONLINE: 12 DEC 20XX

\section{KEYWORDS}

learning app, teaching, web based education, ICT approaches, modelling..



\section{OVERVIEW}

The present study follows the line and field of researches outlined in series of publications [1]-[5] in the field of learning applications in the digital based education process and in conjunction the following terms are defined:

- $\quad$ Learning application (app) - An ICT based tool using didactical methodology with clear defined pedagogical goal in certain scientific field or fields;

- Complete high-technology environment (CHTE) - Persistent time dominant interactive technology environment of the individual, who 
perceives, processes and transfers the information through the digital technologies;

- High interactive generation (HIG) - A social defined community situated in CHTE.

Digital generation was replaced by high interactive generation. As such generation it accomplishes their dominant part of its needs through various smart devices and reasonably it puts into question the didactical approaches of the instructors or lecturers in the educational process in which it is participant itself.

From other side the educational process integrates a broad set of ICT [6][14][25][28]-[30], but when this process lacks attributes and teacher's technology tools, adequate to student's perceptions, could be difficult high quality of the educational process to be achieved.

As suggested [1] aspects in development of the WEB based learning applications could be differentiated into two main groups:

- Technological (Hardware and software);

- Pedagogical.

In these developments as a leading premise pedagogical goal is determined, but the chosen technology and approaches would serve as a methodology for achieving this goal. The integrity of these aspects defines a process development framework. But, the main difference, between certain software product development outside of the education and software with main characteristic of learning application, defines the following aspects:

- Pedagogical goals;

- Didactical model;

- Student model;

- High measurable interactivity implementation[5].

Considering the application development process constant factors has been set. These factors have key impact on final product and also in the applying on the educational process of this learning application. These factors set up straight dependency of the learning application and its exploitation by the pedagogical goals [1][15]-[17], didactical model, student model and functional measurable interactivity.

\section{Application Modelling}

In the field of learning apps intended for knowledge providing via digital resource representation, there are number of implementations particularly in the engineering specialties, as reviewed in [18]-[21] and some of it are very sophisticated in technological perspective, but there could be noted certain flaws in these examples to be used as learning tool like their lack of clear pedagogy aspect, dependency of cross-platform compatibility, requirement of certain preparations, some compilations or installation procedures. This definitely limits accessibility, usage and improvements in the world of hyper connectivity. 
This study doesn't evaluate these app's technical functionalities rather it emphasize on the lack of fully integrated didactical and student models in it which may twist the whole educational process, including some improper or inaccurate assessments alongside syllabus.

We assume that there are several technological principles on which the learning app lies:

- Information flow;

- Interactivity;

- Multimodality;

- CSD Integrity;

- Spatial and anytime access;

- Cross-platform independency.

As far as the last two principles are clearly self-defined and interactivity was deeply exposed [5], the cross-scientific domain (CSD) integrity strictly demands seamless integration of two parts - software and pedagogy (didactical model and student model). The first one principle, information flow, defines how topic related knowledge should flows through the active education time window of the application. Multimodality will be discussed little further.

To achieve more educational output values the above principles should be regarded in certain high education project for developing WEB based learning tool for specific topic. After the phase of requirements analysis, in phase of formalization and modelling there are certain factors to be regarded. Considering the specific subject of the application and field of knowledge we accept as guiding line here recent discovery of scientist of Max Planck Institute that the human brain uses several frequency bands for the flow of information between lower and higher areas where visual cortex processes visual information[22]. And so we assume information flow of the active educational application-time-window should consist of information sub-flows sourced from each component. We also assume that this sub-flows shouldn't be interrupted each other. This mean the time of activity of all components must be equal and also equal to the active phase of the educational main time window. According to this we do information flow formalization.

Let

$$
c_{i} \in C=\left\{c_{1}, c, \ldots c_{n}\right\}
$$

where

$C$ - set of all learning application components.

$c_{i}-\mathrm{i}^{\text {th }}$ component of the learning application.

So we could accept that:

$$
\exists(\operatorname{App}(t)) \rightarrow(\operatorname{PETW}(t) \wedge \operatorname{AETW}(t))
$$

where 
$A p p(t)$ - learning application (time dependent) runtime.

$\operatorname{PETW}(t)$ - passive educational application-time-window (time dependent).

$\operatorname{AETW}(t)$ - active educational application-time-window (time dependent).

Here $A E T W(t)$ gets in its active phase after the student login where this is the time point where $\operatorname{PETW}(t)$ terminates its phase.

And thus

$$
\left.\left(\forall c_{i} \in A p p\right) \rightarrow a_{i}(t)\right) \rightarrow\left(a_{i}(t)=A E T W(t)\right)
$$

where

$A p p$ - learning application executable

$a_{i}(t)$ - active phase of $\mathrm{i}^{\text {th }}$ component of the application

Following the above principles and formulation a conceptualization of WEB based learning application is presented in fig.1. Walk through the design stage of the application an UML sequence diagram was chosen to do the conceptualization despite the statement that this type of diagram is meant to be used in one single scenario. But to justify it we put into high level of abstraction educational process as main scenario.

A conceptualization examination describes tree main initiations - of Didactical model, of the Student modelError! Reference source not found. and Topic Information Flow.

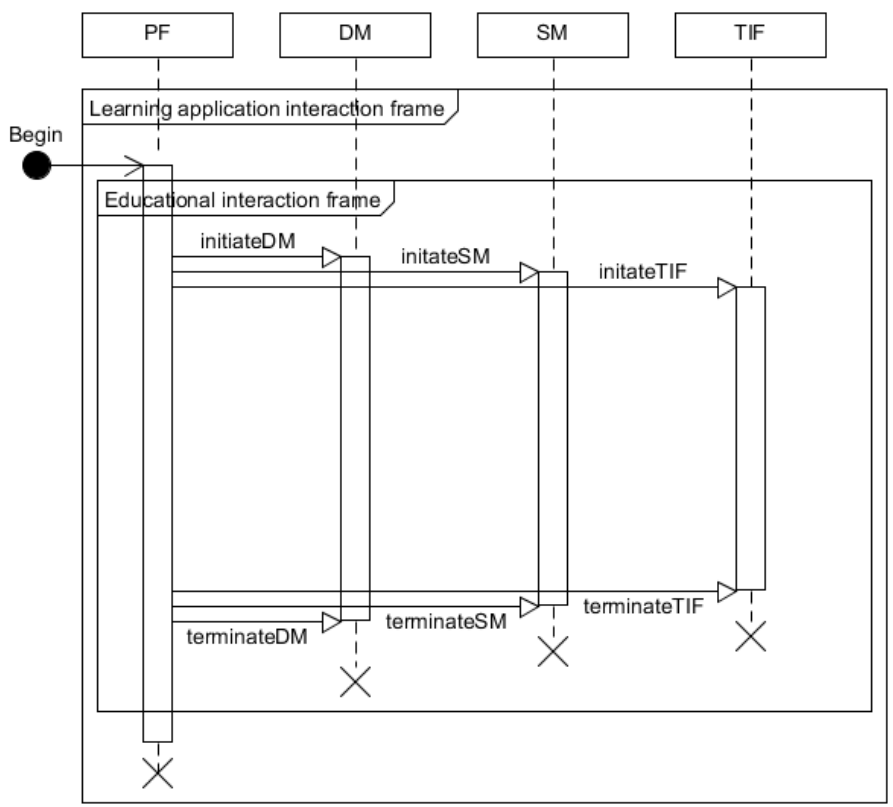


Figure 1: Conceptualization of the WEB based learning application.

Thus objectivize the implementation of pedagogy in the software, which is crucial difference between common software product and software intended for learning purposes. The second main conceptualization characteristic is that digital educational process place in educational interaction frame all the active educational phases. Main active objects (participants) of the conceptualization are Program flow (PF), Didactical model (DM), Student model (SM) and Topic Information flow (TIF).

The multimodality is other key characteristic of the learning app. We assume an approach of defining asynchronous information channels for the same fragments of the topic related knowledge represented via different type of data text, images and speech which is direct referenced by[22][24] and to put aside the declining learning-styles beliefs[23]. As an abstract thinking this rely on increasing flexibility in perception, located in special areas of the frontal lobe that are responsible for it.

In addition we assume as a pedagogical aspect a methodology, based on the adoption of the constructivist theory. So, the student could be able to construct knowledge based on its own prior experience assisted with mentor/teacher. But in digital context of the learning process to construct knowledge in learning app we rely on physiological human characteristic - sensitivity, which is correlated with a stimulus. And when data are represented through various types - image, text and sound this will increase the detection levels and responds to stimulus.

Stimulus reception opens the sensory channels[27], and that's exactly is what we strive to embed into learning app. In order to accomplish it there should be expansion of the number of the visual interactive controls in parallel of human stimulus perception for every component of the educational application-timewindow as expressed in (3).

\section{CONCLUSIONS}

The presented in this paper conceptualization might be used as common guidelines when the teaching online instrument is on demand. As stated in application modelling section in given development process of the web based learning application during the first stages the above principles have to be applied in order to implement all characteristics of the standard educational process into its digital equivalent.

\section{REFERENCES}

[1] V. Atanasov, K. Kalev, "Some aspects in the design and development of learning applications for engineering specialties", Proceedings on: 62nd International scientific conference'2019, Publishing house of University of Mining and Geology "St. Ivan Rilski", Sofia, Bulgaria, pp.126-129, 2019, ISSN: 2682-9525; 
[2] V. Atanasov, A. Ivanova, "Student modelling in a web-based platform for learning games composing", The 13th International Scientific Conference eLearning and Software for Education, Bucharest, vol.2, pp.272-279, 2017, https://doi.org/10.12753/2066-026x-17-040;

[3] V. Atanasov, A. Ivanova. "A WEB based Platform for Learning Games composing - Basic Concept and Architectural Aspects", In: Proceedings of eLearning'15 International Conference, Berlin, Germany, pp.256 - 261, 2015, ISBN: 2367 - 6698;

[4] N. Stoianov, K. Kalev, "Cyber potential vulnerabilities in the defense system", Publishing house NMU Vasil Levski, Veliko Tyrnovo, Bulgaria, Annual of NMU Vasil Levski, Veliko Tyrnovo, vol.2, pp.21-28, 2019, ISSN 1312-6148;

[5] V. T. Atanasov and A. S. Ivanova, "A Framework for Measurement of Interactivity of Digital Learning Resources," 2019 42nd International Convention on Information and Communication Technology, Electronics and Microelectronics (MIPRO), Opatija, Croatia, 2019, pp. 649-654, doi: 10.23919/MIPRO.2019.8757052;

[6] S. N. M. Mohamad, M. A. M. Sallehb, S. Salamc, "Factors Affecting Lecturers Motivation in Using Online Teaching Tools", Procedia - Social and Behavioral Sciences, 2015, doi: 10.1016/j.sbspro.2015.06.378;

[7] D. Al-Fraihat, M. Joy, R. Masa'deh, I. Sinclair, "Evaluating E-learning systems success: An empirical study, Computers in Human Behavior", Elsevier Ltd., vol. 102, pp.67-86, 2020, ISSN: 0747-5632, https://doi.org/10.1016/j.chb.2019.08.004;

[8] D. Shah, J., French, J. Rankin L. Breslow, "Using Video to Tie Engineering Themes to Foundational Concepts", ASEE Annual Conference and Exposition, Indianapolis, Indiana, 2014, ISSN: 2153-5868;

[9] K.O. Slavyanov, "Fuzzy logic procedure for drawing up a psychological profile of learners for better perception in courses", Environment. Technology. Resources. Rezekne, Latvia, Proceedings of the 12th International Scientific and Practical Conference. vol. II, pp.136-140, 2019, ISSN: 1691-5402, doi: http://dx.doi.org/10.17770/etr2019vol2.4073;

[10] P. K. Nair, F. Ali, I. C. Leong, "Factors affecting acceptance and use of ReWIND: Validating the extended unified theory of acceptance and use of technology", Interactive Technology and Smart Education, vol.12(3), pp.183-201, 2015, ISSN: 1741-5659;

[11] Y. Zhao, K. Bandyopadhyay, S. Bandyopadhyay, "What matters most in online sap-enabled course learning? A system view of determinants", Proceedings of the 52nd Hawaii international conference on system sciences, 2019, ISBN: 978-0-9981331-2-6, doi: 10.24251/HICSS.2019.914;

[12] B. Šumak, M. HeričKo, M. PušNik, "A meta-analysis of e-learning technology acceptance: The role of user types and e-learning technology types", Computers in Human Behavior, vol. 27(6), pp.2067-2077, 2011, doi: https://doi.org/10.1016/j.chb.2011.08.005; 
[13] B. Trilling, C. Fadel, "21st Century Skills: Learning for Life in Our Times", Jossey-Bass, San Francisco, CA, 2012, doi:10.5860/choice.47-5788;

[14] M. Vasileva, M. Lambeva, "Analysis of the objectivity of assessment in the field of distance learning, Collection of papers, International scientific conference, "Vasil Levski" National Military University - Artillery, Air Defense and CIS Faculty, Shumen, Bulgaria, pp. 237-242, 2015, ISSN 2367-7902;

[15] B. Haßler, L. Major and S. Hennessy, "Tablet use in schools: A critical review of the evidence for learning outcomes", Journal of Computer Assisted Learning, vol. 32 (2), pp. 139-156, 2016, doi: https://doi.org/10.1111/jcal.12123;

[16] H. Fjørtoft, "Multimodal digital classroom assessments", Computers \& Education, Elsevier Ltd., vol. 152, article 103892, 2020, ISSN: 0360-1315,;

[17] O. Noroozia, H. Dehghanzadehb, E. A. Talaeeb, "A systematic review on the impacts of game-based learning on argumentation skills", Entertainment Computing, Entertainment Computing, Elsevier B.V., vol. 35, article 100369, 2020, ISSN: 1875-9521, doi: https://doi.org/10.1016/j.entcom.2020.100369;

[18] J. Ma, L. Yu, J. M. Ye, T. Chen, "MCMG simulator: A unified simulation framework for CPU and graphic GPU", Journal of Computer and System Sciences, Elsevier Inc., vol. 81, pp.57-71, 2015, ISSN: 0022-0000, doi: http://dx.doi.org/10.1016/j.jcss.2014.06.017;

[19] T. Halic, W. Ahn, S. De, "Optimization Model for Web Based Multimodal Interactive Simulations", Expert Syst Appl., vol. 42(12), pp.5245-5255, 2015, doi: 10.1016/j.eswa.2015.02.026;

[20] C. Yehezkel,M. Ronen, M. Eliahu, "Easy CPU: Simulation-based Learning of Computer Architecture at the Introductory Level", International Journal of Engineering Education, vol. 25(2), pp.228-238, 2009, ISSN: 0949-149X;

[21] F. Ryckbosch, F., Polfliet, S.,Eeckhout, L., "Fast, Accurate, and Validated FullSystem Software Simulation of x86 Hardware," in IEEE Micro, vol. 30, no. 6, pp. 46-56, 2010, doi: 10.1109/MM.2010.95;

[22] G. Michalareas, J. Vezoli, S. van Pelt, J. M. Schoffelen, H. Kennedy, P. Fries, "Alpha-Beta and Gamma Rhythms Subserve Feedback and Feedforward Influences among Human Visual Cortical Areas". Neuron, vol., 89(2), pp.384397, 2016, doi: https://doi.org/10.1016/j.neuron.2015.12.018;

[23] S. Nancekivell, P. Shah, S. Gelman, "Maybe They're Born With It, or Maybe It's Experience Toward a Deeper Understanding of the Learning Style Myth", Journal of Educational Psychology, vol. 112, No. 2, pp.221-235, 2020, ISSN: 0022-0663, doi: http://dx.doi.org/10.1037/edu0000366;

[24] Y. Cao, C. Summerfield, H. Park, B. Giordano, C. Kayser, "Causal Inference in the Multisensory Brain", Neuron, 2019, ISSN: 1097-4199, doi: https://doi.org/10.1016/j.neuron.2019.03.043;

[25] M. Lambeva, M. Vasileva "An approach to the integration of information systems in education", Proceedings of the second conference on innovative 
teaching methods (ITM 2017), 28-29 june 2017, pp. 110-116, Publishing house "Science and economics", Varna, 2017, ISBN: 978-954-21-0930-3;

[26]M. Vasileva, M., Lambeva, "Analysis of the objectivity of assessment in the field of distance learning", Collection of papers, International scientific conference, "Vasil Levski" National Military University - Artillery, Air Defense and CIS Faculty, Shumen, Bulgaria, pp.237-242, 2015, ISSN: 2367-7902;

[27] J. P. Ewert, "Stimulus Perception, in book: The Behavior of Animals: Mechanisms, Function And Evolution, Edition: 1, Wiley, chapter I, pp.13-40, 2004, ISBN-13: 9780631231257;

[28] M. Loukantchevsky, N. Kostadinov, H. Avakyan, "A Testbed of Nondeterminism in Educational Context", Proceedings of the 20th International Conference on Computer Systems and Technologies, Association for Computing Machinery, New York ,United States, pp. 304-307, 2019, ISBN: 978-1-4503-7149-0, https://doi.org/10.1145/3345252.3345260;

[29] M. K.Sotirov, Y. I. Tsonev, Implementation of Gamification in the University Classrooms, Conference proceedings of seventh national conference "Elearning in higher education", 2018, Sofia, p.232-236, ISBN 978-954-07-45091 ;

[30] M. K.Sotirov, Y. I. Tsonev, About Possibilities for Gamification in the Learning Process Using Moodle, Conference proceedings of seventh national conference "E-learning in higher education", 2018, Sofia, p.303-307, ISBN 978-954-07-4509-1. 